\title{
Occupational Health Hazards Prevailing among Healthcare Workers in Developing Countries
}

\author{
Henrietta Osaretin Owie ${ }^{1}$ and Paschal Awingura Apanga ${ }^{2 *}$ \\ ${ }^{1}$ Surulere, Lagos, Nigeria
}

${ }^{2}$ Talensi District Hospital, Ghana Health Service, Tongo, Ghana

\begin{abstract}
Introduction: Occupational health is a neglected public health issue among healthcare workers in developing countries. This has exposed healthcare workers in developing countries to various forms of hazards which have had negative consequences on their wellbeing and performance at work. The aim of this research was to explore the forms of occupational hazards prevalent with their associated risk factors in developing countries and to recommend measures that can be put in place to remedy the situation.
\end{abstract}

Methods: Relevant literature were selected from search results from databases such as Medline, CINAHL, EMBASE, PsycINFO and Google search engine were included in the review.

Results: The review revealed that blood borne diseases, musculoskeletal problems, latex allergy, tuberculosis, violence and work-related stress were the common occupational hazards among healthcare workers and this was largely blamed on several healthcare system issues.

Conclusion: Developing countries should prioritize occupational health and safety issues by investing heavily into standard infection control measures and training of healthcare workers on work safety. Mounting surveillance on occupational hazards and implementing policies that will protect the safety of healthcare workers is also key.

Keywords: Occupational hazards; Healthcare workers; Safety; Developing countries

\section{Introduction}

The International Labour Organization (ILO) estimates that 160 million people from the world's workforce suffer from work-related diseases such as musculoskeletal diseases and mental health problems, while 270 million fatal and non-fatal work-related accidents results in over 350, 000 casualties and over two million work-related deaths each year which are all attributable to occupational hazards [1]. These findings are similar to the report of the World Health Organization (WHO) which estimated occupational diseases worldwide to be 217 million cases [2]. Evidence shows that many of these diseases are preventable but problems like under reporting, poor surveillance and several other factors have been known to influence occupational health hazards $[3,4]$. The burden caused by work-related accidents and illnesses on workers' health are incalculable. According to ILO, $4 \%$ of the world's annual Gross Domestic Profit (GDP) is lost as a result of occupational hazards as employers are faced with loss of skilled staff, absenteeism, migration, early retirements and high insurance premiums due to exposure from occupational accidents and diseases [1].

Occupational hazard is defined as the "potential risk to the health of a person emerging from an unhealthy environment" which is a significant public health issue. It can also be referred to as any activity, materials, processes or situation that is likely to cause an accident or disease at the work place [4]. Although improvement in occupational health have been seen in many developed countries, however, the protection of workers from work-related disorders is not a priority in many developing countries, partly because several other health issues have competed with occupational health. This situation has existed for long owing to various socio-economic, cultural and political challenges which often make occupational health not prioritized [5]. This has made occupational health and safety which is a fundamental right in maintaining workers' wellbeing to remain neglected in developing countries $[5,6]$.
The lack of adequate laws and policies regulating the work environment exposes many workers to hazards which may be life threatening. Occupational health and safety laws represent only about $10 \%$ of the population in developing countries, omitting many major hazardous industries and occupations like the health sector [6,7]. Even in circumstances where occupational health and safety laws exist, workers are being employed in conditions which not only deprive them of their dignity and value but also expose them to a number of occupational accidents. This often results in the deterioration of health and wellbeing as this is evident in many African countries where occupationally acquired illnesses such as tropical diseases and poor nutrition affect their performance at work [6].

Although occupational hazards are mostly underreported due to inadequate research, it has also revealed a lot of occupational diseases/ injuries in sub-Saharan Africa and Asia with developing countries lacking the necessary expertise and resources to manage it [6,7]. It has also been argued that the management of medical waste poses a very high risk to healthcare in developing countries. This includes poor handling, collection, sorting, segregation and disposal of medical waste such as sharps, medical devices, blood and body tissues [8]. Unsafe disposal of medical wastes is a major challenge in developing countries as it contributes largely to occupational injuries and infections [8,9]. Additionally, Masum et al. found that the increase in occupational health hazards in developing countries are largely blamed on Healthcare

*Corresponding author: Paschal Awingura Apanga, MD, MPH, Talensi Distric Hospital, Ghana Health Service, Tongo, Ghana, Tel: +233249667938; E-mail: awingura@yahoo.com

Received June 07, 2016; Accepted June 27, 2016; Published July 04, 2016

Citation: Owie HO, Apanga PA (2016) Occupational Health Hazards Prevailing among Healthcare Workers in Developing Countries. J AIDS Clin Res 7: 596. doi:10.4172/2155-6113.1000596

Copyright: ( 2016 Owie HO, et al. This is an open-access article distributed under the terms of the Creative Commons Attribution License, which permits unrestricted use, distribution, and reproduction in any medium, provided the original author and source are credited. 
Workers (HCWs) not practicing universal safety precautions such as hand washing, wearing of gloves and the usage of Protective Personal Equipment (PPE) [8]. This unsafe practice increases the risk of injuries as well as transmission of infections to HCWs.

Occupational hazards as a result of exposure to infectious blood borne pathogens including Human Immunodeficiency Virus (HIV), Hepatitis B Virus (HBV) and other health related events are among the most serious health risks faced by HCWs in developing countries [10-13]. These exposures do not only affect the quality of care being delivered by HCWs but also affects the safety and well-being of care providers. Majority of these occupational health hazards are known to occur in developing countries but only $4 \%$ of these hazards are being reported with few papers on occupational hazards affecting HCWs in developing countries $[10,14]$. This review paper will bring to light the common occupational health hazards with associated risk factors affecting HCWs in developing countries and to make recommendations to tackle these challenges.

\section{Methods}

The research methodology is a narrative literature review; a systematic approach was applied in the search for studies through electronic databases such as Medline, CINAHL, EMBASE, PsycINFO and Google search engine. The search terms that were used include: occupational health, occupational hazards, occupational diseases, occupational injuries, occupational accidents, healthcare workers and developing countries. The inclusion criteria were studies focusing on occupational hazards affecting HCWs in developing countries in subSaharan Africa, South Asia and South America as well as studies that were conducted in English. Studies that did not meet the inclusion criteria were excluded from the review.

The search terms yielded a total of 974 papers after a thorough database search was done. The papers retrieved were further scrutinized by going through their titles, abstracts and full text of the papers in which forty three (43) papers were included in the review. Also, three (3) relevant references obtained from citation tracking where included in the final review. This summed up to a total forty six (46) papers for the review. Figure 1 shows literature selection process.

The findings extracted from the selected studies in the final review were analyzed thematically. The synthesized findings were categorized into appropriate themes according to the major occupational hazards prevailing among HCWs in developing countries. This revealed the following themes: transmission of blood borne pathogens, tuberculosis, musculoskeletal diseases, work-related stress, latex allergies and work related violence.

\section{Current Status of Knowledge}

\section{Transmission of blood borne pathogens}

Blood borne pathogens which include HIV, HBV and Hepatitis C Virus (HCV) are the commonly acquired occupational diseases in developing countries [11-13]. Lee observed that majority of occupational acquired blood borne diseases by HCWs were as a result of needle stick injuries [15]. These findings were consistent with studies by Orji et al. and Fasunloro and Owotade in Nigeria $[16,17]$. Additionally, improper disposal of medical waste such as needles and other sharps has been found to cause injuries on HCWs which can also transmit blood borne diseases [10]. Lee in 2009 argued that the increase in acquisition of blood borne diseases by HCWs in developing countries is due to the high prevalence of HIV, HBV and

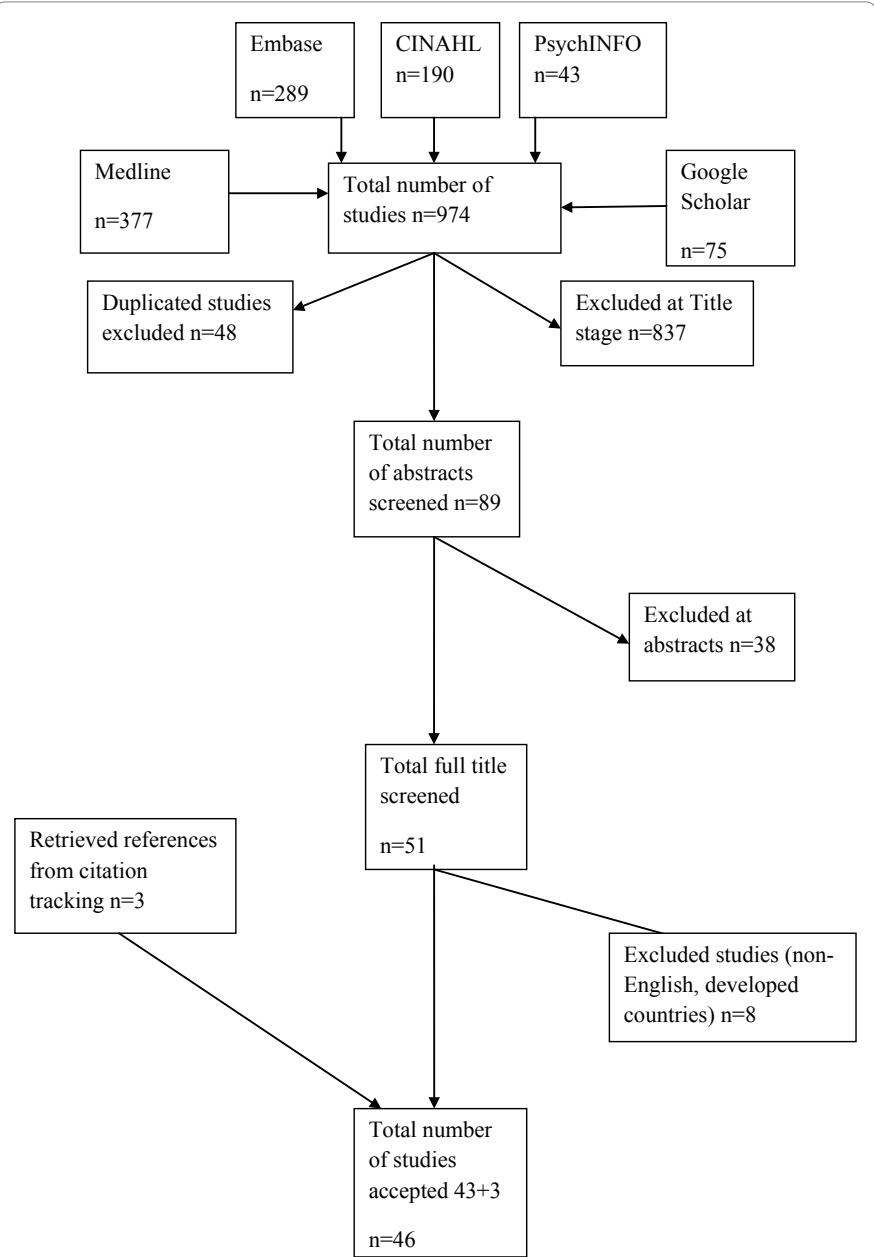

Figure 1: Flow chart of the study selection process.

HBC, hence making them more likely to acquire such blood borne diseases [15].

Also, the lack of a comprehensive vaccination coverage among HCWs against HBV, poor use or non-availability of post-exposure prophylaxis (PEP) and lack of adherence to standard safety infection control measures such as use of gloves, washing of hands and usage of disinfectants increases the risk of transmission of blood borne diseases $[15,17]$.

\section{Transmission of tuberculosis}

Tuberculosis (TB) is a major public health problem and an occupational hazard affecting HCWs in developing countries [18-22]. The transmission of this disease according to Baussano et al. occurs through droplet nuclei aerosolized by patients with pulmonary TB [23]. In rural India, Pai et al. observed that $50 \%$ of HCWs had Latent Tuberculosis Infection (LTBI) and this was in line with studies by Joshi et al. who found that LTBI among HCWs in low and middle income countries ranged from $33-70 \%[22,24]$.

Several factors accounts for the increase in Tuberculosis among HCWs. Healthcare workers who worked in health facilities with a high ratio of Tuberculosis patients per health worker were at an increased risk of LTBI [20]. Pai et al. revealed that HCWs who were much older were at greater risk of acquiring this occupational disease as compared 
to younger ones [22]. Studies have also reported that HCWs who had worked for over ten years were at greater risk than their counterparts who worked for lesser years. It was also observed that HCWs who worked in locations within the health facility such as laboratories, tuberculosis inpatient wards, general medicine unit and emergency units were at an increased risk of acquiring LTBI because they are more likely to spend more time with Tuberculosis patients than their peers in administrative section of the facility $[22,24]$.

The recognition of $\mathrm{TB}$ as an occupational hazard in developed countries brought about the emergence of Multidrug Resistant TB (MDR-TB) in health establishments thus leading to the development of effective infection control measures implemented for the reduction of TB transmission [23]. However, implementing infection control measures in developing countries are too expensive as a result of limited resources coupled with the lack of sufficient evidence of its efficacy in countries with high prevalence of TB, hence, detection of TB cases and treatment are done using the Directly Observed Treatment Short-course (DOTS) strategy, which limits infected HCWs from performing their usual task during the treatment process [23]. Likewise, in developing countries, HCWs do not have any form of access to self-protection when handling infected TB patients, therefore resulting in them avoiding contacts with such patients which may lead to suboptimal care of the patients [25].

\section{Musculoskeletal disease}

Several studies identified Musculoskeletal Disease (MSD) as an occupational hazard which is highly prevalent among HCWs [26-28]. These studies revealed high prevalence of musculoskeletal problems among HCWs. Healthcare workers had experienced at least one or more symptoms of MSD over the previous twelve months. Muralidharan et al. in India found that the prevalence of MSD was 78\% and more common among orthodontists and oral physicians whilst Adegoke et al. in Nigeria, observed that Work-Related Musculoskeletal disorders (WMSDs) among physiotherapists was $91.3 \%$. These disorders were associated with prolonged standing postures, continuous movements and the use of force during work. More so, it was noted that all practitioners above 45 years of age had musculoskeletal problems; hence, increased age was found as a risk factor for MSD. Also, HCWs who attended to more than 40 patients per working day complained of musculoskeletal symptoms $[27,28]$.

Most commonly affected areas among HCWs with musculoskeletal problems were the neck followed by the lower back, shoulders and wrists [28]. This is contrary to findings by other studies which reported the lower back as the most common site followed by the neck $[26,27]$. Factors responsible for musculoskeletal problems were frequent lifting or transferring of dependent patients, bending, treating large number of people; working in the same position for long hours; prolonged standing posture, performing manual therapy and psychological stress [26-28]. The effects of MSD on HCWs were observed as an on-going problem, workers with MSD complained of having pain for a period of seven days. Others requested for sick leave, hospital admissions and reduction in work activity and leisure activity [26-29]. Karahan in 2008 argued that more than half of the healthcare workers received medication while $4.2 \%$ had to undergo a surgical procedure as a result of lower back pain [29].

In order to cope with musculoskeletal pains, some HCWs developed the habit of adjusting their position and or the position of their patients which includes adjusting bed height. They also chose appropriate techniques best suitable for their comfort rather than causing discomfort. Requesting for assistance when handling patients was part of the measures adopted. This made some HCWs more likely to select methods best suitable for their comfort at work rather than meeting the needs of their patients [27].

\section{Work-related stress}

Work-related stress have been identified as a common occupational hazard prevailing among HCWs in developing countries [16,30,31]. The Researchers argue that the demanding nature of work performed by HCWs is responsible for stress that they suffer. Orji et al. in Nigeria found that $83.3 \%$ of HCWs reported work-related stress in the obstetrics and gynaecology unit of a Nigerian teaching hospital [16]. Work-related stress was associated with excess workload, long working hours, numerous shift duties and a high number of patient attendances. Similarly, a study conducted in Pakistan demonstrated that more than half of HCWs had experienced stress in the line of duty. Zaeem et al. attributed the causes of stress among HCWs to be due to travelling long distance to work, poor communication between patients, low socioeconomic status, irregular medical supplies at the health facility and lack of career structure for HCWs and insufficient financial income earned by HCWs per month [31].

Furthermore, occupational stress among HCWs has been argued to be responsible for high level of job burnout [32]. Younger nurses were more at risk of experiencing high burnout than their older counterparts. Additionally, nurses working in the surgical department tend to be more exposed to occupational stress as compared to their peers in other departments as they were more likely to stand for longer hours during work. Burnout during work among HCWs was observed to cause physical fatigue, emotional exhaustion, depersonalization and psychosomatic problems which increased feelings of failure [30]. Other effects of work-related stress reported were alcohol intoxication, drug abuse, poor job satisfaction and stress induced hypertension [16]. These negative effects of work-related stress prevent HCWs from achieving effective work performance.

\section{Latex allergies (gloves)}

The prevalence of latex allergy among HCWs have revealed that latex allergy occurs from daily usage of gloves which is a major source of occupational hazard among HCWs [33,34]. In Sri-Lanka, a study revealed that $16.3 \%$ of HCWs had experienced latex allergy related symptoms that ranged from immediate reactions from contact dermatitis to type 1 hypersensitivity reactions and these symptoms were influenced by the type and duration of healthcare services provided [33]. These findings were in conformity with studies by Ozkan and Gokdogan in Turkey who found the prevalence of latex allergy among HCW s to be $19.1 \%$. Healthcare workers who worked in emergency units were 4.8 times more at risk of developing latex allergy as compared to their counterparts who worked in other units [35]. It was also observed that HCWs who wore gloves for a period of an hour and above within a working day were at an increased risk of latex allergy [33]. In addition, workers who had close contact with those who wore gloves complained of having persistent symptoms of latex allergy reactions which lasted for a year.

\section{Work-related violence}

Researchers have shown that violence in the workplace is a significant problem among HCWs in developing countries [36-40]. The common type of violence faced by HCWs are verbal and physical as observed by Celik et al. who reported $91.1 \%$ of HCWs who had suffered abuse either verbally or physically whilst $32.8 \%$ were abused both physically and verbally [39]. These findings were similar to studies 
by Bob et al. who reported $88.6 \%$ of HCWs who had suffered verbal violence. Also, Khademloo et al. revealed that $95.9 \%$ of HCWs were verbally abused compared to $29.1 \%$ who were physically abused. The Authors argue that these abuses followed cancellation of appointment, long waiting time at the health facility and during payment of patient's bill.

Shogni et al. noted that verbal abuse occurred frequently during the morning shift whilst physical violence occurred during the evening shift; this was as a result of overcrowding of patients in the health facility during both shifts. Additionally, the rate of verbal and physical abuse were higher among nurses who were graduates as they were more likely to discuss their problems with their fellow HCWs which tends to cause conflict between them and their perpetrators [40,41]. However, Bob et al. found that common causes of violence against HCWs were as a result of alcoholic intoxication and drugs by perpetrators.

According to Azodo et al. and Bobbi et al. non-physical violence were reportedly much more common among HCWs than physical violence $[38,42]$. The Authors observed that swearing, threatening, shouting and sexual harassment against workers constituted the majority of violence whilst physical attack constituted the lowest. Also, it was found that female HCWs were major victims of exposure to violence and sexual harassment $[27,38]$. This was contrary to other studies that demonstrated that male HCWs were more exposed to violence than their female counterparts [36,41].

In addition, the risk of experiencing an abuse was found to be higher in nurses working in inpatient units of a healthcare facility as well as nurses who were handling the first aid kit were more subjected to violence than those in other positions $[39,41]$. Perpetrators of violence were majorly reported to be patients and their relatives, and instruments that were used in exerting violence were mainly surgical blades, telephones, shoes or bags [36-38].

\section{Conclusion}

This study has revealed the various forms of common occupational health hazards that HCWs encounter whilst providing care to clients in developing countries. It has also demonstrated that occupational health and safety has simply been neglected in developing countries and this has negatively impacted on the performance of HCWs [43]. It is therefore imperative for developing countries to consider the following recommendations to protect the basic rights and wellbeing of HCWs.

A comprehensive vaccination programme should be introduced in all healthcare facilities to vaccinate workers against Hepatitis B to reduce its risk of acquisition [44]. Post-exposure prophylaxis should be made available to HCWs who sustain needle stick injuries [43]. Health facilities should also have proper medical waste disposal systems to dispose of waste [10]. Additionally, Personal Protective Equipment (PPE) should be made accessible to HCWs with a written plan on how and when to use it [45]. Posters should also be posted on healthcare facilities to remind workers of universal safety precautions [43]. All HCWs should receive periodic trainings on universal health and safety precautions to enhance the safety of patients and healthcare providers. Surveillance systems on occupational hazards among HCWs should be set up in healthcare facilities to detect early report and respond appropriately to such hazards [46].

Furthermore, developing countries should institute the ILO standards on occupational safety and health as it provides essential tools for governments, employers and workers to establish practices that confer maximum safety at work [1]. There is also the need for developing countries to invest heavily into occupational health and safety research as it will influence positively on policy and decision making regarding health and safety issues among HCWs.

\section{Authors Contribution}

$\mathrm{HOO}$ conceived the study. $\mathrm{HOO}$ and PAA designed the study and wrote the first draft. Both authors read and approved the final submission.

\section{References}

1. International Labour Organization (2016) International Labour Standards on occupational safety and health.

2. World Health Organization (2016) International statistical classification of diseases and related health problems (ICD-10) in occupational health.

3. Takele T, Mengesha A (2006) Occupational health and safety. Ethiopia Public Health Training Initiative.

4. Fasunloro A, Owotade FJ (2004) Occupational hazards among clinical dental staff. J Contemp Dent Pract 5: 134-152.

5. Nuwayhid IA (2004) Occupational health research in developing countries: a partner for social justice. Am J Public Health 94: 1916-1921.

6. Ahasan MR, Partanen T (2001) Occupational health and safety in the least developed countries--a simple case of neglect. J Epidemiol 11: 74-80.

7. LaDou J (2003) International Occupational Health. International Journal of Hygiene and Environmental Health 206: 303-313.

8. Masum A, William TO, Mosharraf HS (2011) Assessment of occupational and environmental safety associated with medical waste disposal in developing countries: A qualitative approach. Safety Science.

9. Sed N, Gesase AP, Massele AY (2011) Dangers of Injections overuse in developing countries with a high HIVIAIDS prevalence: A review on HIV risk hazards, traumatic effects and other blood borne infections. Asian Pacific Journal of Tropical Diseases 1: 158-163.

10. Philips EK, Simwale OJ, Chung MJ, Parker G, Perry J (2012) Risk of blood borne pathogen exposure among Zambian healthcare workers. Journal of Infection and Public Health 5: 242-249.

11. Abeje FG, Azage M (2015) Hepatitis B vaccine knowledge and vaccination status among health care workers of Bahir Dar City Administration, Northwest Ethiopia: A cross sectional study. BMC Infect Dis 15: 30.

12. Beyera GK, Beyen TK (2014) Epidemiology of exposure to HIVIAIDS risky conditions in healthcare settings: the case of health facilities in Gondar City, North West Ethiopia. BMC Public Health 14: 1283.

13. Gupta S, Wong EG, Kushner AL (2014) Scarcity of protective items against HIV and other blood borne infections in 13 low- and middle-income countries. Trop Med Int Health 19: 1384-1390.

14. Rantanen J, Lehtinen S, Savolainen K (2004) The opportunities and obstacles to collaboration between the developing and developed countries in the field of occupational health. Toxicology 198: 63-74.

15. Lee R (2009) Occupational transmission of blood borne diseases to healthcare workers in developing countries: Meeting the challenges. Journal of hospital infection 72: 285-291.

16. Orji EO, Fasubaa OB, Onwudiegwu U, Dare FO, Ogunniyi SO (2002) Occupational health hazards among health care workers in an obstetrics and gynaecology unit of a Nigerian teaching hospital. J Obstet Gynaecol 22: 75-78.

17. Fasunloro A, Owotade FJ (2004) Occupational hazards among clinical dental staff. J Contemp Dent Pract 5: 134-152.

18. Stuart RL, Grayson ML (2000) Health care workers and tuberculosis. Aust N Z J Med 30: 367-372.

19. Cuhadaroglu C, Erelel M, Tabak L, Kilicaslan Z (2002) Increased risk of tuberculosis in health care workers: A retrospective survey at a teaching hospital in Istanbul, Turkey. BMC Infect Dis 2: 14.

20. Kanyerere HS, Salaniponi FM (2003) Tuberculosis in health care workers in a central hospital in Malawi. Int J Tuberc Lung Dis 7: 489-492.

21. Jesudas CD, Thangakunam B (2013) Tuberculosis risk in health care workers Indian J Chest Dis Allied Sci 55: 149-154. 
Citation: Owie HO, Apanga PA (2016) Occupational Health Hazards Prevailing among Healthcare Workers in Developing Countries. J AIDS Clin Res 7: 596. doi:10.4172/2155-6113.1000596

Page 5 of 5

22. Nicolau I, Ling D, Tian L, Lienhardt C, Pai M (2012) Research questions and priorities for tuberculosis: A survey of published systematic reviews and metaanalyses. PLoS One 7: e42479.

23. Baussano I, Nunn P, Williams B, Pivetta E, Bugiani M, et al. (2011) Tuberculosis among health care workers. Emerg Infect Dis 17: 488-494.

24. Joshi R, Reingold AL, Menzies D, Pai M (2006) Tuberculosis among healthcare workers in low- and middle-income countries: A systematic review. PLoS Med 3: e494.

25. Coblens F (2007) Tuberculosis Risks for healthcare workers in Africa. Journals of the royal society of topical medicine and hygiene $44: 324-326$.

26. Tezel A (2005) Musculoskeletal complaints among a group of Turkish nurses. Int J Neurosci 115: 871-880.

27. Adegoke BO, Akodu AK, Oyeyemi AL (2008) Work-related musculoskeletal disorders among Nigerian physiotherapists. BMC Musculoskelet Disord 9: 112.

28. Muralidhar S, Singh PK, Jain RK, Malhotra M, Bala M (2010) Needle stick injuries among health care workers in a tertiary care hospital of India. Indian J Med Res 131: 405-410.

29. Karahan A, Kav S, Abbasoglu A, Dogan N (2009) Low back pain: Prevalence and associated risk factors among hospital staff. J Adv Nurs 65: 516-524.

30. Ashtari Z, Farhady Y, Khodaee MR (2009) Relationship between job burnout and work performance in a sample of Iranian mental health staff. Afr J Psychiatry (Johannesbg) 12: 71-74

31. Zaeem H, Zafar I, Atif R (2016) Job stress among community health workers: A multi-method study from Pakistan. International of Mental Health Systems.

32. Palfi I, Boncz I, Oláh A, Betlehem J (2008) In response to Wu S, Zhu W, Wang Z, Wang M \& Lan Y. (2007) Relationship between burnout and occupational stress among nurses in China. Journal of Advanced Nursing 59(3), 233-239. J Adv Nurs 61: 720-721.

33. Amarasekera M, Nadeeka R, Savithri S. Maheshika J (2010) Prevalence of Latex allergy among healthcare workers. International Journal of Occupational Medicine and Environmental Health 23: 391-396.

34. Phaswana SM, Naidoo S (2013) The prevalence of latex sensitisation and allergy and associated risk factors among healthcare workers using hypoallergenic latex gloves at King Edward VIII Hospital, KwaZulu-Natal South Africa: A cross-sectional study 3: e002900.

35. Ozkan O, Gökdogan F (2003) The prevalence of latex allergy among health care workers in Bolu (Turkey). Dermatol Nurs 15: 543-547, 554.

36. Khademloo M, Moonesi FS, Gholizade H (2013) Health care violence and abuse towards nurses in hospitals in north of Iran. Glob J Health Sci 5: 211-216.

37. Ünsal Atan S, Baysan Arabaci L, Sirin A, Isler A, Donmez S, et al. (2013) Violence experienced by nurses at six university hospitals in Turkey. J Psychiatr Ment Health Nurs 20: 882-889.

38. Azodo CC, Ezeja EB, Ehikhamenor EE (2011) Occupational violence against dental professionals in southern Nigeria. Afr Health Sci 11: 486-492.

39. Celik SS, Celik Y, AÄŸirbaÅŸ I, UÄŸurluoÄŸlu O (2007) Verbal and physical abuse against nurses in Turkey. Int Nurs Rev 54: 359-366.

40. Ergun FS, karadakovan A (2005) Violence towards nursing staff in emergency departments in one Turkish city. International Journal of Nursing review 52 154-160.

41. Shogni M, Mahnaz S, Fateme S, Shiva H, Sedighe S, et al. (2008) Workplace violence and abuse against nurses against in Iran. Elsevier 2: 184-193.

42. Bobbi S (2008) Workplace violence isn't always physical: A one year experience of a group of registered psychiatric nurses.

43. Sadoh WE, Fawole AO, Sadoh AE, Oladimeji AO, Sotiloye OS (2006) Practice of universal precautions among healthcare workers. J Natl Med Assoc 98: 722 726.

44. Ziglam H, El-Hattab M, Shingheer N, Zorgani A, Elahmer O (2013) Hepatitis $B$ vaccination status among healthcare workers in a tertiary care hospital in Tripoli, Libya. J Infect Public Health 6: 246-251.

45. Matanock A, Arwady MA, Ayscue P, Forrester JD, Gaddis B, et al. (2014) Ebola virus disease cases among health care workers not working in Ebola treatment units--Liberia, June-August, 2014. MMWR Morb Mortal Wkly Rep 63: 1077-1081.

46. Rajkumari N, Thanbuana BT, John NV Gunjiyal J, Mathur P, et al. (2014) A prospective look at the burden of sharps injuries and splashes among trauma health care workers in developing countries: true picture or tip of iceberg. Injury 45: $1470-1478$. 